\title{
Modeling water, heat, and oxygen budgets in a tidally dominated estuarine pond
}

\author{
Nicole G. Beck ${ }^{1, *}$, Andrew T. Fisher ${ }^{1,2}$, Kenneth W. Bruland ${ }^{2,3}$ \\ ${ }^{1}$ Department of Earth Sciences, ${ }^{2}$ Center for the Dynamics of the Land-Sea Interface and ${ }^{3}$ Department of Ocean Sciences, \\ University of California at Santa Cruz, Santa Cruz, California 95064, USA
}

\begin{abstract}
We present a methodology to model water, heat, and dissolved oxygen budgets on short time scales within a shallow estuarine environment using limited local water quality and climatic data. A tidally restricted eutrophic pond in Elkhorn Slough, California, experiences extreme diel dissolved oxygen (DO) variations during warm sunny days and neap tidal cycles. Empirical relationships between biological metabolism (measured as DO variations) and physical parameters are derived using time-series hydrographic data from the site. A simple box model predicts the time-series structure of water depth, water temperature, and DO concentrations within the pond as a function of the tidal cycle and local climate over 10 to 15 d simulation periods. Parametric analyses illustrate applications of the model to predict thermal and geochemical responses to hydrologic, chemical, and climatic alterations to the system. This study also initiates preliminary investigations of the fundamental processes influencing DO dynamics within a natural wetland environment, and could be used to explore the potential response to various physical and chemical alterations prior to restoration or management adjustments. Future box models of wetland geochemistry should include carbon and nutrient budgets to create a more sensitive model, and to allow more rigorous evaluations of the role decreased nutrient inputs would play in alleviating eutrophic conditions.
\end{abstract}

KEY WORDS: Estuary · Wetland restoration model $\cdot$ Diel ecosystem metabolism $\cdot$ Eutrophication

\section{INTRODUCTION}

Biogeochemical cycling in aquatic environments results from the interaction of physical, chemical, and biological processes. Physical conditions drive biological and geochemical processes on short time scales. These processes may also feed back on one another, allowing extreme conditions to develop. For example, photosynthetic growth rates vary with the supply of the most limiting nutrient, or can be inhibited by elevated levels of toxic metals or organic compounds. In turn, photosynthesis and respiration can dramatically alter the dissolved oxygen (DO), nutrient, and trace metal concentrations in the water column (Stumm \& Morgan 1996, Schlesinger 1997).

\footnotetext{
*E-mail: nbeck@es.ucsc.edu
}

The physical, biological, and geochemical balance can be fragile in shallow environments where geochemical reservoirs are relatively small compared to short-term fluxes. Natural diel biogeochemical variations are amplified as a result of elevated biological metabolism in coastal waters receiving significant nutrient inputs from anthropogenic sources (Kemp \& Boyton 1980, D'Avanzo \& Kremer 1994, D'Avanzo et al. 1996, Beck \& Bruland 2000). Nutrient enrichment from agricultural and urban runoff has resulted in eutrophication of many coastal waters. For example, extreme phytoplankton growth in portions of the Chesapeake Bay has created seasonal anoxic bottom waters and subsequent fish kills (Officer et al. 1984, Cooper \& Bush 1991). Tidal restrictions that increase water residence times are also a common result of human intervention in estuarine environments. Diking due to agriculture, grazing or mosquito abatement alters the flow 
dynamics and may have marked effects on biogeochemical cycling (Montague et al. 1987). For example, restricted flow along the coast of Long Island Sound was determined to cause dramatic changes in sediment chemistry, acidifying overlying waters and elevating levels of dissolved $\mathrm{Pb}, \mathrm{Cd}, \mathrm{Ag}$, and $\mathrm{Cd}$ (Anisfeld \& Benoit 1997).

There is a need to predict and evaluate geochemical variations on short time scales, since the geochemistry and biological interactions at the base of the food chain fundamentally influence ecosystem health. DO is a proxy for community metabolism, is readily measurable, and provides a simple indication of ecological health and vitality (Odum 1971). The ability to predict daily biogeochemical cycling, including DO variations, improves our assessments of the health of shallow aquatic systems. The research site presented herein is tidally restricted and receives a significant amount of nutrient-rich runoff from neighboring agricultural areas. We present a simple box model that couples physical, biological, and chemical processes to show how limited in situ water quality data can be used to simulate biological, chemical, and physical dynamics. Our model conserves water volume, heat, and oxygen as distinct, linked budgets. We use time-series depth, temperature and dissolved oxygen data collected every 15 or $30 \mathrm{~min}$ in a wetland system in Elkhorn Slough, California to tune the model. The model performs 3 main functions: (1) predict water depth $\left(D_{\text {pond }}\right)$ and water temperature $\left(T_{\text {pond }}\right)$ in the pond as a function of local climate and tides; (2) model DO concentration $\left([D O]_{p}\right)$ within the pond as a result of physical and biological processes; and (3) evaluate responses of the DO budget to various physical alteration scenarios. In order to assess the daily photosynthetic and respiratory oxygen dynamics, we present a methodology to develop empirical relationships between community metabolism and physical conditions within this eutrophic system. This approach is applicable to other sites, but would require site-specific tuning due to variations in physical hydraulics, ecological systematics, and geochemical processes.

\section{FIELD AREA}

Elkhorn Slough (Fig. 1) is a shallow coastal estuary located near Moss Landing, California, USA, between Santa Cruz and Monterey, on the edge of the Monterey Bay National Marine Sanctuary. Elkhorn Slough is composed of a main channel that extends inland $8 \mathrm{~km}$ with associated tidal flats occupying over $10 \mathrm{~km}^{2}$. Azevedo Pond is part of the wetland system associated with Elkhorn Slough and is bordered on the west by a Pacific Railway track and on the east by a $100 \mathrm{~m}$ long

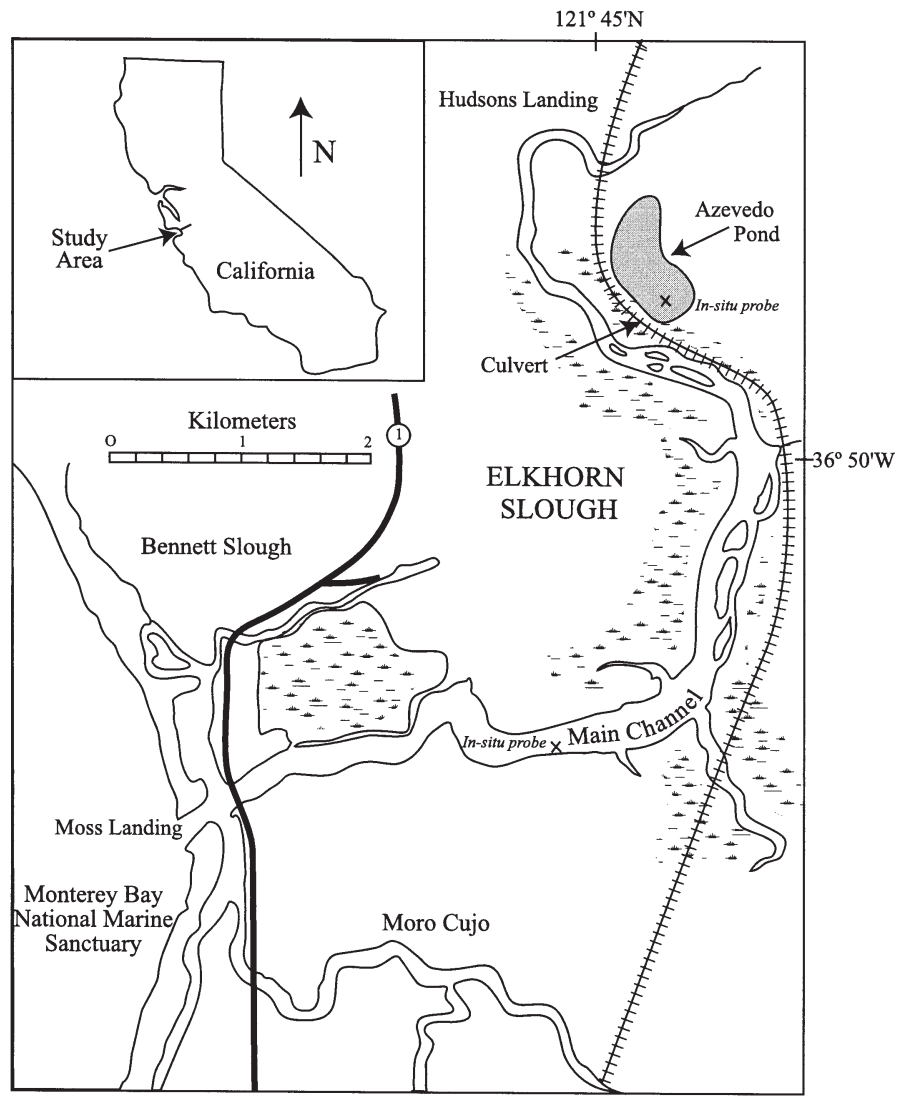

Fig. 1. Site map of Azevedo Pond, Elkhorn Slough, California (adapted from Beck \& Bruland 2000)

hill ( $\sim 5$ to $20^{\circ}$ slope). Tidal flushing of the pond is controlled by flow through a $1.9 \mathrm{~m}$ diameter culvert located beneath the railroad track, isolating Azevedo Pond from the main channel of Elkhorn Slough. Azevedo Pond receives nutrient-rich agricultural runoff from neighboring fields and, due to periodic tidal flow restrictions, experiences sustained periods of minimal tidal flushing. An elevation gradient between the main channel and Azevedo Pond prevents flow into the pond until the tidal height within the main channel exceeds the elevation of the culvert at the entrance of the pond. Detailed geochemical studies during the summer months have shown ammonia concentrations in excess of $15 \mu \mathrm{M}$ and phosphate concentrations in excess of $5 \mu \mathrm{M}$ in Azevedo Pond (Beck \& Bruland 2000). Winter analyses have recorded $\mathrm{NO}_{x}$ (nitrate and nitrite) concentrations exceeding $75 \mu \mathrm{M}$ (T. Chapin pers. comm.). For the purposes of this study, we assume that macronutrients ( $\mathrm{N}$ and $\mathrm{P}$ ) do not limit primary productivity.

Azevedo Pond experiences nighttime suboxia when low tidal amplitudes are coupled with warm sunny days. Neap tidal cycles decrease depth variations within the pond (Fig. 2A). During the spring and sum- 


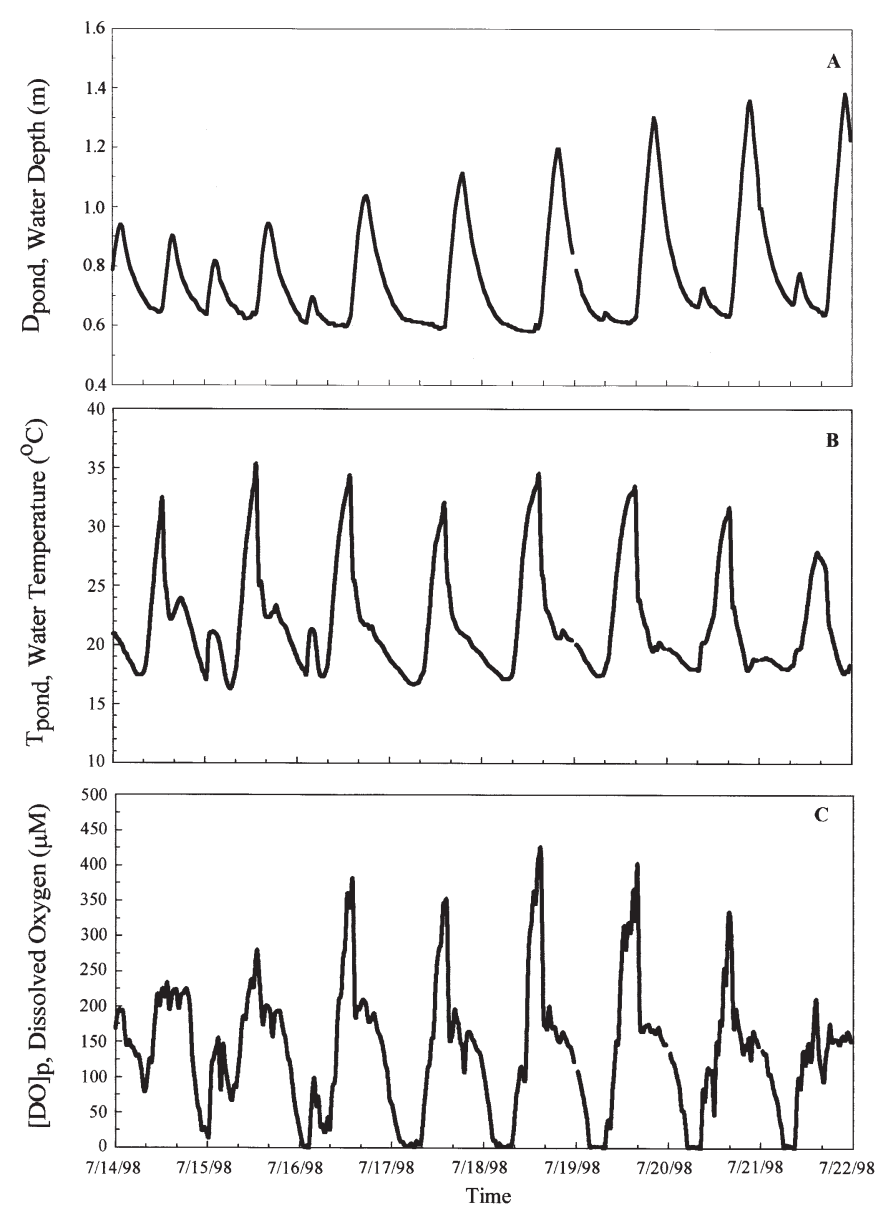

Fig. 2. Time-series of (A) water column depths, (B) water temperature, and (C) DO measurements collected in Azevedo Pond, July 14 to August 22, 1998 mer months, when shortwave radiation and air temperatures are at a maximum, water temperatures within Azevedo Pond can exceed $30^{\circ} \mathrm{C}$ (Fig. 2B). Decreased mixing within the pond, coupled with high water temperatures and light intensities, elevate biological production rates, which has a pronounced effect on daily DO variations (Wetzel 1975, Stumm \& Morgan 1996). Daily DO variations in Azevedo Pond reach extremes of $>400 \mu \mathrm{M}$ ( $>250 \%$ saturation) during the day to $<5 \mu \mathrm{M}$ (suboxic) at night (Fig. 2C) (Beck \& Bruland 2000).

\section{MODEL DEVELOPMENT}

A box model allows us to evaluate conditions under which suboxic events will occur, given current and potential future driving forces. The model couples physical weather and tidal data to transient changes of 3 linked budgets: water volume, heat, and DO (Fig. 3). Hydrographic data were collected with a YSI 6000 multi-parameter instrument from 2 locations in Elkhorn Slough (collected on 15 or 30 min intervals continuously since September 1995) and provided by the Elkhorn Slough National Estuarine Research Reserve (ESNERR). One in situ probe was installed in Azevedo Pond, and the other in an adjacent area of the main channel of Elkhorn Slough approximately $3.5 \mathrm{~km}$ from the mouth of estuary (Fig. 1). Both probes were located approximately $0.5 \mathrm{~m}$ above the sediments. Climatic data were provided by the University of California at Santa Cruz (UCSC) Real-time Environmental Information Network and Analysis System (REINAS) project
Fig. 3. Schematic of model structure, illustrating primary inputs, fluxes, reservoirs, and calculated parameters. The main inputs to the model are tidal variations and local weather data (ovals). These fluxes regulate 3 distinct budgets (rectangles), which can be used to calculate parameters such as water depth $\left(D_{\text {pond }}\right)$, pond temperature $\left(T_{\text {pond }}\right)$, and DO concentration $\left([\mathrm{DO}]_{\mathrm{p}}\right)$ (diamonds)

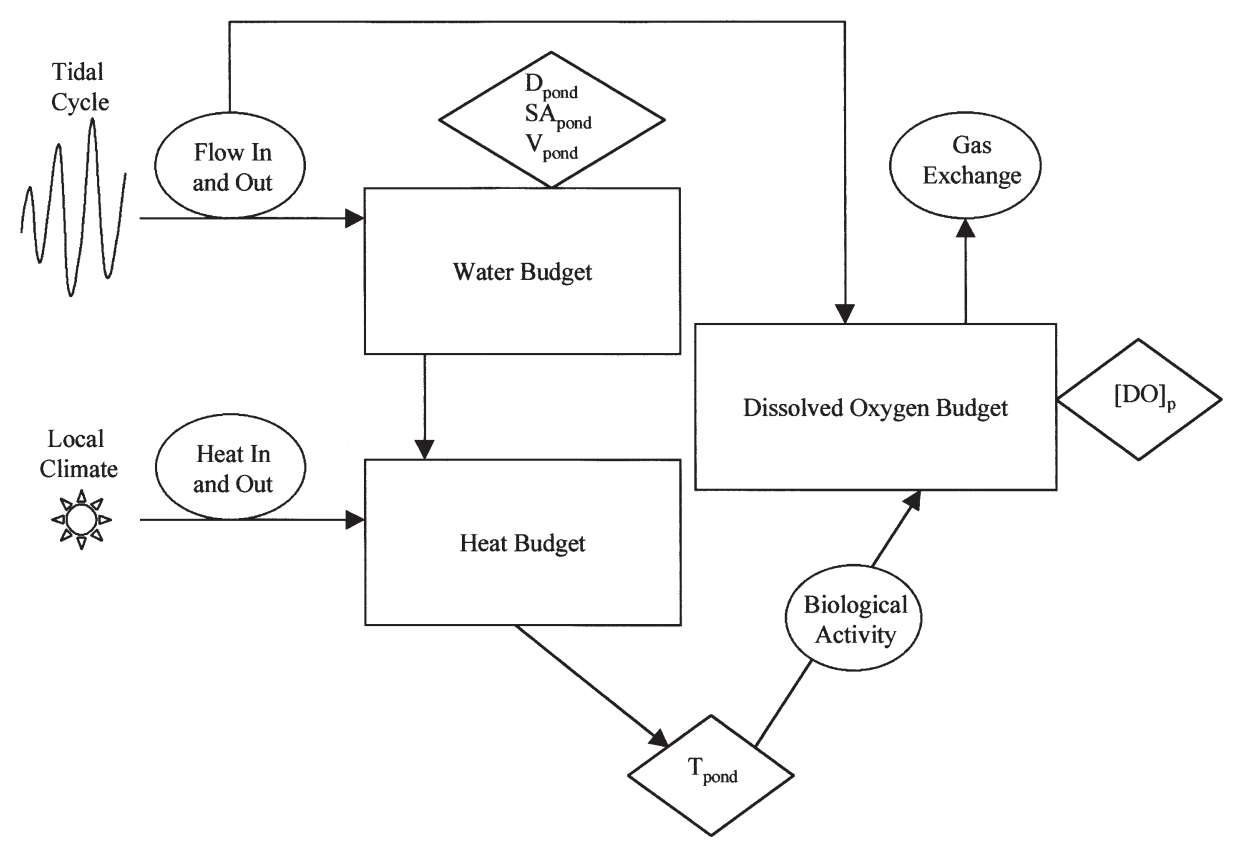


Table 1. Notation of variables

\begin{tabular}{|c|c|c|c|}
\hline Variable & Value & Units & Source \\
\hline$A_{\text {in/out }}$ (cross-sectional area of water within culvert) & calc & $\mathrm{m}^{2}$ & \\
\hline $\mathrm{ADO}_{\text {in }}$ (advected DO from inflow waters) & calc & $\mu \mathrm{mol} \mathrm{min} \operatorname{mon}^{-1}$ & \\
\hline $\mathrm{ADO}_{\text {out }}$ (advected flux of DO from pond) & calc & $\mu \mathrm{mol} \min ^{-1}$ & \\
\hline$C_{\mathrm{p}}$ (specific heat capacity) & 4200 & $\mathrm{~J} \mathrm{~kg}^{-1}{ }^{\circ} \mathrm{C}^{-1}$ & Dingman (1994) \\
\hline$D_{\text {c }}$ (depth of water at culvert) & calc & $\mathrm{m}$ & \\
\hline$D_{\mathrm{DO}}($ diffusion flux of $\mathrm{DO})$ & calc & $\mu \mathrm{mol} \mathrm{min} \operatorname{mon}^{-1}$ & D'Avanzo (1996) \\
\hline$D_{\text {pond }}($ depth of the pond) & calc & $\mathrm{m}$ & \\
\hline $\mathrm{DO}_{\text {in }}(\mathrm{DO}$ in flux to pond) & calc & $\mu \mathrm{mol} \mathrm{min}{ }^{-1}$ & \\
\hline $\mathrm{DO}_{\text {out }}$ (DO out flux from pond) & calc & $\mu \mathrm{mol} \mathrm{min} \operatorname{mon}^{-1}$ & \\
\hline $\mathrm{DO}_{\text {pond }}(\mathrm{DO}$ reservoir) & calc & $\mu \mathrm{mol} \mathrm{min}{ }^{-1}$ & \\
\hline$[\mathrm{DO}]_{\mathrm{p}}(\mathrm{DO}$ concentration of pond) & calc & $\mu \mathrm{M}$ & \\
\hline$[D O]_{\text {sat }}$ (DO saturation concentration for a given $T_{\mathrm{mc}}$ or $T_{\text {pond }}$ ) & calc & $\mu \mathrm{M}$ & Broeker \& Peng (1982) \\
\hline$e_{\mathrm{a}}($ vapor pressure of air) & calc & $\mathrm{mb}$ & Dingman (1994) \\
\hline$e_{\text {as }}$ (vapor pressure of air at saturation) & calc & $\mathrm{mb}$ & Dingman (1994) \\
\hline$e_{\mathrm{s}}$ (vapor pressure at water surface) & calc & $\mathrm{mb}$ & Dingman (1994) \\
\hline$E$ (evaporation rate) & calc & $\mathrm{m} \min ^{-1}$ & Dingman (1994) \\
\hline$E_{\text {base }}$ (base elevation of the bottom of the pond) & 0.56 & $\mathrm{~m}$ & Philip Williams \& Ass. (1993) \\
\hline$E_{\mathrm{c}}($ culvert elevation) & $1.08,1.32^{1996}$ & $\mathrm{~m}$ & Philip Williams \& Ass. (1993) \\
\hline$E_{\text {pond }}$ (pond elevation) & calc & $\mathrm{m}$ & Philip Williams \& Ass. (1993) \\
\hline$E_{\mathrm{t}}$ (tidal elevation) & obs & $\mathrm{m}$ & WXTide32 \\
\hline$E_{\mathrm{w}}$ (emissivity of liquid water) & 0.95 & Unitless & \\
\hline$K$ (gas exchange coefficient) & calc & $\mathrm{g} \mathrm{O}_{2} \mathrm{~m}^{-2} \mathrm{~s}^{-1}$ & D'Avanzo (1996) \\
\hline$K_{\mathrm{e}}$ (mass-transfer coefficient) & $7 \times 10^{-4}$ & $\mathrm{~cm} \mathrm{mb}^{-1} \mathrm{~km}^{-1}$ & Dingman (1994) \\
\hline$L$ (latent heat of vaporization) & $2.56 \times 10^{6}$ & $\mathrm{~J} \mathrm{~kg}^{-1}$ & \\
\hline$L_{\text {atm }}$ (longwave radiation incoming from the atmosphere) & obs & $\mathrm{J} \mathrm{m}^{-2} \mathrm{~s}^{-1}$ & REINAS \\
\hline$L_{\text {ch }}($ length of channel) & 62.5 & $\mathrm{~m}$ & Measured in field \\
\hline$L_{\mathrm{w}}$ (long wave radiation reflected by water surface) & calc & $\mathrm{J} \mathrm{m}^{-2} \mathrm{~s}^{-1}$ & Dingman (1994) \\
\hline$n$ (Manning roughness coefficient) & varies & Unitless & Fig. 8 \\
\hline$p$ (atmospheric pressure) & obs & $\mathrm{Mb}$ & REINAS \\
\hline Ps (photosynthetic rate) & varies & $\mu \mathrm{M} \mathrm{O}_{2} \min ^{-1}$ & Fig. 6 \\
\hline$Q_{\mathrm{a}}$ (net heat advected with water flow in and out of pond) & calc & $\mathrm{J} \mathrm{min}^{-1}$ & Dunne \& Leopold (1978) \\
\hline$Q_{\mathrm{e}}$ (energy lost to evaporation) & calc & $\mathrm{J} \min ^{-1}$ & Dingman (1994) \\
\hline$Q_{\mathrm{h}}$ (sensible heat transfer from water surface to atmosphere) & calc & $\mathrm{J} \min ^{-1}$ & Dunne \& Leopold (1978) \\
\hline$Q_{\mathrm{lw}}($ net longwave radiation) & calc & $\mathrm{J} \min ^{-1}$ & Dingman (1994) \\
\hline$Q_{\text {pond }}$ (energy reservoir) & calc & $\mathrm{J} \min ^{-1}$ & Dunne \& Leopold (1978) \\
\hline$Q_{\mathrm{rs}}$ (reflected short wave radiation) & calc & $\mathrm{J} \min ^{-1}$ & Dunne \& Leopold (1978) \\
\hline$Q_{\mathrm{sw}}$ (incoming shortwave radiation) & obs & $\mathrm{J} \mathrm{m}^{-2} \mathrm{~s}^{-1}$ & REINAS \\
\hline$Q_{\text {sw-SA }}$ (incoming solar radiation over pond surface area) & calc & $\mathrm{J} \min ^{-1}$ & \\
\hline$R$ (hydraulic radius) & calc & Unitless & Fetter (1994) \\
\hline $\operatorname{Re}$ (respiration rate) & varies & $\mu \mathrm{M} \mathrm{O}_{2} \min ^{-1}$ & Fig. 5 \\
\hline$S$ (slope of water surface entering or leaving the pond) & calc & Unitless & Fetter (1994) \\
\hline $\mathrm{SA}_{\text {pond }}$ (surface area of the pond) & calc & $\mathrm{m}^{2}$ & Philip Williams \& Ass. (1993) \\
\hline SD (DO saturation deficit of pond) & calc & $\mu \mathrm{M}$ & \\
\hline$T_{\text {air }}$ (air temperature) & obs & ${ }^{\circ} \mathrm{C}$ & REINAS \\
\hline$T_{\mathrm{mc}}$ (main channel water temperature) & $14-17$ & ${ }^{\circ} \mathrm{C}$ & Measured in field \\
\hline$T_{\text {pond }}$ (pond temperature) & calc/obs & ${ }^{\circ} \mathrm{C}$ & Dingman (1994)/ NERRS \\
\hline$v_{a}($ wind speed $)$ & obs & $\mathrm{m}^{2} \mathrm{~s}^{-1}$ & REINAS \\
\hline$V_{\text {in }}$ (water volume input flux) & calc & $\mathrm{m}^{3} \min ^{-1}$ & Fetter (1994) \\
\hline$V_{\text {out }}$ (water volume output flux) & calc & $\mathrm{m}^{3} \min ^{-1}$ & Fetter (1994) \\
\hline$V_{\text {pond }}$ (water volume reservoir) & calc & $\mathrm{m}^{3} \min ^{-1}$ & Fetter (1994) \\
\hline$W_{\mathrm{a}}$ (relative humidity) & obs & Unitless & REINAS \\
\hline$W_{\mathrm{c}}$ (width of culvert) & 1.9 & $\mathrm{~m}$ & Measured in field \\
\hline$\rho_{\mathrm{w}}$ (density of water) & $10^{3}$ & $\mathrm{~kg} \mathrm{~m}^{-3}$ & \\
\hline$\sigma$ (Stefan-Boltzman constant) & $5.67 \times 10^{-8}$ & $\mathrm{~J} \mathrm{~m}^{-2} \mathrm{~s}^{-1} \mathrm{~K}^{-4}$ & \\
\hline$\alpha$ (reflective albedo of the water surface) & 0.03 & Unitless & Dunne \& Leopold (1978) \\
\hline
\end{tabular}


and collected at a meteorological station located $18 \mathrm{~km}$ southwest of Azevedo Pond. Additional meteorological data used in model simulations of climatic variations was provided by the Bay Area Air Quality Management District (BAAQMD), and collected at weather station \#7905 located in Alviso, California (located $70 \mathrm{~km} \mathrm{NE}$ of Azevedo Pond). Some of the limitations of the model may be attributed to the location specific in situ hydrographic data used to calibrate the model. Daily tidal predictions for Elkhorn were calculated with WXTide32 (available at: http://www.geocities.com/Silicon Valley/Horizon; accessed on: January 1, 2000). Physical dimensions, ground survey data, and stage curves (volume, surface area, and depth) are based on an earlier hydrologic study (Philip Williams \& Ass. 1993). The notation for all of the variables is defined in Table 1.

\section{Water budget}

The water flux within Azevedo Pond is controlled by the local tidal cycle such that $V_{\text {pond }}=V_{\text {in }}-V_{\text {out }}$. Fig. 4 depicts the flow dynamics of the pond, and equations for the water budget ( $\left.V_{\text {pond }}\right)$ are listed in Table 2. All physical elevations have been referenced to mean lower low water (MLLW). Using geometric relationships between the length of the inlet channel, the cross-sectional area of the culvert and the tidal cycle, we modeled the filling and draining of Azevedo Pond with the Manning equation (Fetter 1994). Variables include the frictional slope of the channel $(S)$, the wetted perimeter of the culvert $(R)$, the Manning roughness coefficient $(n)$, and the crosssectional area of water within the culvert $(A)$. Volume changes due to groundwater seepage and evapora-
Table 2. Water volume budget equations

\begin{tabular}{|ll|}
\hline$V_{\text {pond }}=V_{\text {in }}-V_{\text {out }}$ & 1.1 \\
$V_{\text {in } / \text { out }}=S^{1 / 2} \times R^{2 / 3} \times n^{-1} \times A$ & 1.2 \\
$S_{\text {in }}=\left(E_{\mathrm{t}}-E_{\text {pond }}\right) \times L_{\mathrm{ch}}{ }^{-1}$ & 1.3 \\
$S_{\text {out }}=\left(E_{\text {pond }}-E_{\mathrm{t}}\right) \times L_{\mathrm{ch}}{ }^{-1}$ & 1.4 \\
$R=\left(D_{\mathrm{c}} \times W_{\mathrm{c}}\right) \times\left(2 \times D_{\mathrm{c}}+W_{\mathrm{c}}\right)^{-1}$ & 1.5 \\
$D_{\mathrm{c}(\text { in })}=E_{\text {pond }}-E_{\mathrm{c}}$ & 1.6 \\
$E_{\text {pond }}=E_{\text {base }}+0.22867+3.2741 \mathrm{E}-5 \times V_{\text {pond }}-1.5078 \mathrm{E}-10 \times V_{\text {pond }}{ }^{2}$ & 1.7 \\
$D_{\mathrm{c}(\text { out })}=E_{\mathrm{t}}-E_{\mathrm{c}}$ & 1.8 \\
$n=-0.175 \times D_{\mathrm{c}}+0.08$ if $D_{\mathrm{c}}<0.4 \mathrm{~m}_{i} n=0.01$ if $D_{\mathrm{c}} \geq 0.4 \mathrm{~m}$ & 1.9 \\
$A_{\text {in }}=\left(E_{\mathrm{t}}-E_{\mathrm{c}}\right) \times W_{\mathrm{c}}$ & 1.10 \\
$A_{\text {out }}=\left(E_{\text {pond }}-E_{\mathrm{c}}\right) \times W_{\mathrm{c}}$ & 1.11 \\
$\mathrm{SA}_{\text {pond }}=-56580+22663 \times \log V_{\text {pond }}$ & 1.12 \\
$D_{\text {pond }}=E_{\text {pond }}-E_{\text {base }}$ & 1.13 \\
\end{tabular}

tion were assumed to be negligible on the time scales considered with the model. Because this model was constructed to evaluate extreme dissolved oxygen variations, which tend to occur in the dry summer months, the influence of precipitation on the water volume, temperature, and DO variations is insignificant and was neglected.

\section{Heat budget}

The heat stored in the pond $\left(Q_{\text {pond }}\right)$ was calculated with a heat balance equation (Table 3; Dunne \& Leopold 1978) and used to predict water temperature variations $\left(T_{\text {pond }}\right)$.

Weather data needed to run the model include incoming shortwave radiation $\left(Q_{\mathrm{sw}}\right)$, air temperature $\left(T_{\text {air }}\right)$, relative humidity $\left(W_{\mathrm{a}}\right)$, wind speed $\left(v_{\mathrm{a}}\right)$, longwave radiation incoming from the atmosphere $\left(L_{\mathrm{atm}}\right)$, and atmospheric pressure $(p)$. $Q_{\mathrm{sw}-\mathrm{SA}}$, the incoming shortwave radiation over the surface area of the pond, is balanced by reflective losses $\left(Q_{\mathrm{rs}}\right)$, net longwave radiation $\left(Q_{\mathrm{lw}}\right)$, heat lost to evaporation $\left(Q_{\mathrm{e}}\right)$, sensible heat loss $\left(Q_{\mathrm{h}}\right)$ and the heat advected into or out of the
Fig. 4. Schematic relationship between Azevedo Pond and the main channel of Elkhorn Slough, and the physical variables used to express the geometric interactions within the model

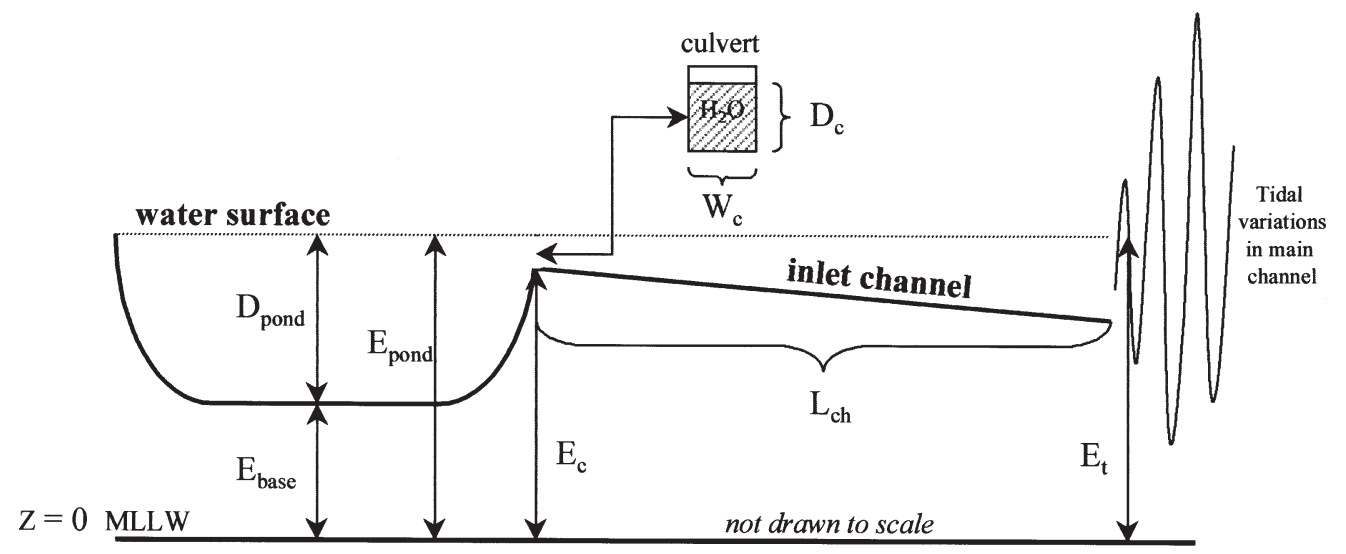


Table 3. Heat budget equations

\begin{tabular}{|c|c|}
\hline$Q_{\text {pond }}=Q_{\mathrm{sw}-\mathrm{SA}}-Q_{\mathrm{rs}} \pm Q_{\mathrm{lw}}-Q_{\mathrm{e}}-Q_{\mathrm{h}} \pm Q_{\mathrm{a}}$ & 2.1 \\
\hline$Q_{\mathrm{sw}-\mathrm{SA}}=Q_{\mathrm{sW}} \times \mathrm{SA}_{\text {pond }}$ & 2.2 \\
\hline$Q_{\mathrm{rs}}=Q_{\mathrm{sw}} \times \alpha$ & 2.3 \\
\hline $\begin{array}{l}Q_{\mathrm{lw}}=\left(L_{\mathrm{atm}}-L_{\mathrm{w}}\right) \times \mathrm{SA}_{\text {pond }} \\
\quad L_{\mathrm{w}}=E_{\mathrm{w}} \times \sigma \times\left(T_{\text {pond }}+273.2\right)^{4}\end{array}$ & $\begin{array}{l}2.4 \\
2.5\end{array}$ \\
\hline$Q_{\mathrm{e}}=E \times \mathrm{SA}_{\text {pond }} \times \rho_{\mathrm{w}} \times L$ & 2.6 \\
\hline $\begin{array}{l}E=K_{\mathrm{e}} \times v_{\mathrm{a}} \times\left(e_{\mathrm{s}}-e_{\mathrm{a}}\right) \\
e_{\mathrm{s}}=6.11\left[\left(17.3 \times T_{\text {pond }}\right) /\left(T_{\text {pond }}+237.3\right)\right]\end{array}$ & $\begin{array}{l}2.7 \\
2.8\end{array}$ \\
\hline $\begin{aligned} e_{\mathrm{a}}= & e_{\mathrm{as}} \times W_{\mathrm{a}} \\
& e_{\mathrm{as}}=6.11^{\left[\left(17.3 \times T_{\mathrm{air}}\right) /\left(T_{\mathrm{air}}+237.3\right)\right]}\end{aligned}$ & $\begin{array}{l}2.9 \\
2.10\end{array}$ \\
\hline$Q_{\mathrm{h}}=Q_{\mathrm{e}} \times 6.1 \times 10^{-4} \times p \times\left(T_{\text {pond }}-T_{\text {air }}\right) \times\left(e_{\mathrm{s}}-e_{\mathrm{a}}\right)^{-1}$ & 2.11 \\
\hline$Q_{\mathrm{a}}=\rho_{W} \times \mathrm{C}_{\mathrm{p}} \times\left(V_{\mathrm{in}} \times T_{\mathrm{mc}}-V_{\text {out }} \times T_{\text {pond }}\right)$ & 2.12 \\
\hline$T_{\text {pond }}=Q_{\text {pond }} \times C_{\mathrm{p}}^{-1} \times \rho_{\mathrm{w}}{ }^{-1} \times V_{\text {pond }^{-1}}$ & 2.13 \\
\hline
\end{tabular}

system by physical water flow $\left(Q_{\mathrm{a}}\right)$. $Q_{\mathrm{rs}}$ can be estimated from the reflective characteristics of liquid water (Table 3, Eq. 2.3). Net $Q_{\mathrm{lw}}$ radiation is the balance between the longwave radiation incoming from the atmosphere $\left(Q_{\mathrm{lw}-\mathrm{R} i}\right.$ recorded at the weather station) and the longwave radiation emitted by the water surface as a function of pond temperature (Table 3, Eqs 2.4 \& 2.5; Dingman 1994). Evaporative losses are calculated using a mass-transfer approach, based on the vapor pressure deficit of the air immediately above the water surface and the rate at which that air is replaced (i.e., wind speed, $v_{a}$ ) (Table 3, Eqs 2.6-2.10). The sensible heat transfer from the water surface to the atmosphere is estimated from the Bowen ratio (sensible heat exchange/latent heat exchange) (Table 3, Eq. 2.11). We then calculate the $T_{\text {pond }}\left({ }^{\circ} \mathrm{C}\right)$ using the specific heat capacity of water (Table 3, Eq. 2.13).

\section{Dissolved oxygen budget}

Both physical and biological processes influence the DO budget. The equations used to evaluate the dissolved oxygen reservoir of the pond $\left(\mathrm{DO}_{\text {pond }}\right)$ are presented in Table $4 . \mathrm{DO}_{\text {pond }}$ can be expressed by the following balance equation:

$\mathrm{DO}_{\text {pond }}=\mathrm{DO}_{\text {in }}-\mathrm{DO}_{\text {out }}$

$=\left[\mathrm{ADO}_{\text {in }}+\left(P S \times V_{\text {pond }}\right)\right]-\left[\mathrm{ADO}_{\text {out }}+\left(\operatorname{Re} \times V_{\text {pond }}\right)\right]$ $\pm D_{\mathrm{DO}}$

Inputs of DO include oxygen advected with inflowing water $\left(\mathrm{ADO}_{\text {in }}\right)$, gas exchange $\left(D_{\mathrm{DO}}\right)$ and photosynthetic oxygen production (Ps). Oxygen is removed from the pond through respiration $(R e)$, loss with outflowing water $\left(\mathrm{ADO}_{\text {out }}\right)$, and gas exchange $\left(D_{\mathrm{DO}}\right)$. We assume that inflowing waters have a DO concentration at satura- tion, and therefore $\mathrm{ADO}_{\text {in }}$ is based on fluid temperatures (Table 4, Eqs 3.3 \& 3.4; Broeker \& Peng 1982). During times of pond drainage, the amount of DO advected out of the pond $\left(\mathrm{ADO}_{\text {out }}\right)$ is a product of the DO concentration of the pond at that time and the volume of water lost (Table 4, Eq. $3.10 \& 3.11$ ). The net DO variation due to gas exchange $\left(D_{\mathrm{DO}}\right)$ is based on an empirical dependence on wind speed, and the relative DO saturation deficit or enrichment of the pond at any particular time (Table 4, Eq. 3.6-3.8; D'Avanzo et al. 1996).

\section{Calculation of $P S$ and $R e$ rates}

Few studies have been conducted on the short-term variability of photosynthetic and respiratory rates from diel DO variations in estuarine environments (Platt et al. 1975). Kemp \& Boyton (1980) evaluated the relative influences of biological and physical processes on daily DO variations within a tidally influenced estuarine ecosystem in Chesapeake Bay. They determined that community photosynthesis contributed about $50 \%$ of the total DO inputs, and respiration accounted for nearly $43 \%$ of the daily losses of DO. Photosynthetic $\mathrm{O}_{2}$ production and respiratory $\mathrm{O}_{2}$ consumption rates are difficult to quantify, and ecosystem metabolism will vary dramatically across aquatic environments. For the purposes of model development, we derived empirical functions for photosynthetic and respiratory oxygen dynamics directly from real-time data collected within Azevedo Pond.

In a eutrophic system such as Azevedo Pond, photosynthetic rates are limited by light rather than nutrient availability (D'Avanzo et al. 1996, Roelke et al. 1999). Our model was created without nutrient or carbon budgets (for which we had no continuous records), with the idea that these reservoirs are essentially infinite. We used the time-series DO data to relate Ps and Re to wa-

Table 4. Dissolved oxygen budget equations

\begin{tabular}{|c|c|}
\hline $\mathrm{DO}_{\text {pond }}=\mathrm{DO}_{\text {in }}-\mathrm{DO}_{\text {out }}$ & 3.1 \\
\hline $\mathrm{DO}_{\text {in }}=\mathrm{ADO}_{\text {in }}+\left(P s \times V_{\text {pond }}\right)+D_{\mathrm{DO}}$ & 3.2 \\
\hline $\mathrm{ADO}_{\text {in }}=[\mathrm{DO}]_{\mathrm{sat}} \times V_{\mathrm{in}}$ & 3.3 \\
\hline$[\mathrm{DO}]_{\mathrm{sat}}=\left(0.0985 \times T_{\mathrm{mc}}^{2}\right)-\left(8.1014 \times T_{\mathrm{mc}}\right)+350.04$ & 3.4 \\
\hline$P S=a Q_{\mathrm{sw}}{ }^{b}$ for a given $T_{\text {pond }}$ & 3.5 \\
\hline$D_{\text {DO }}=K \times \mathrm{SD} \times \mathrm{SA}_{\text {pond }} \times 521$ & 3.6 \\
\hline$K=\left(0.56^{\left(\mathrm{v}_{\mathrm{a}} \times 0.15\right)}\right)$ & 3.7 \\
\hline $\begin{aligned} \mathrm{SD}= & 0.209 \times\left([\mathrm{DO}]_{\mathrm{sat}}-[\mathrm{DO}]_{\mathrm{pond}}\right) \times[\mathrm{DO}]_{\mathrm{sat}}{ }^{-1} \\
& \left([\mathrm{DO}]_{\text {sat }} \text { for a calculated } T_{\text {pond }}\right)\end{aligned}$ & 3.8 \\
\hline $\mathrm{DO}_{\text {out }}=\mathrm{ADO}_{\text {out }}+\left(\operatorname{Re} \times V_{\text {pond }}\right)+D_{\mathrm{DO}}$ & 3.9 \\
\hline $\mathrm{ADO}_{\text {out }}=[\mathrm{DO}]_{\mathrm{p}} \times V_{\text {out }}$ & 3.10 \\
\hline$[\mathrm{DO}]_{\mathrm{p}}=\mathrm{DO}_{\text {pond }} \times V_{\text {pond }}{ }^{-1}$ & 3.11 \\
\hline$R e=0.021 \mathrm{e}^{\left(0.183 \times T_{\text {pond }}\right)}$ & 3.12 \\
\hline
\end{tabular}


ter temperature and shortwave radiation. The relatively shallow water depth (Fig. 2A) should allow the photic zone to penetrate to the surface sediments. We suspect that the photosynthetic community includes a substantial metabolic contribution from benthic algae, in addition to phytoplankton and macrophytes.

We combined data sets from 4 different time periods (September 9-October 9, 1996, May 10-21, 1997, January $10-25,1998$, and July $4-23,1998$ ) to estimate $R e$ as a function of increasing water temperature (Wetzel 1975). Changes in the DO concentrations with time $\left(\partial[\mathrm{DO}]_{\mathrm{p}} / \partial t\right)$ were compared to water temperature during times when $Q_{\mathrm{sw}}=0$ (nighttime) and the depth change of the pond was less than $5 \times 10^{-4} \mathrm{~m} \mathrm{~min}^{-1}$, in an attempt to eliminate any signals resulting from photosynthetic activity or tidal flushing. We also eliminated data during times of suboxia, when $[D O]_{p}=0$. Over 4300 observations, from 4 different months representing each season of the year, were filtered down to 813 data points, and separated into $0.5^{\circ} \mathrm{C}$ intervals. $R e$ was then plotted as a function of water temperature. A good fit for respiration rate as a function of $T_{\text {pond }}$ was determined for an exponential equation, $R e\left(\mu \mathrm{M} \min ^{-1}\right)$ $=0.021 \mathrm{e}^{\left(0.183 \times T_{\text {pond }}\left({ }^{\circ} \mathrm{C}\right)\right)}($ Fig. 5), a relationship similar to that described by Wetzel (1975). The data suggest that when $T_{\text {pond }}$ exceeds $24.5^{\circ} \mathrm{C}$ heterotrophic respiration reaches a maximum $\mathrm{O}_{2}$ removal rate of $1.53 \mu \mathrm{M} \mathrm{min}{ }^{-1}$.

In eutrophic coastal environments, photosynthetic rates are known to be a function of both water temperature and light input (Wetzel 1975, Stumm \& Morgan 1996). Observed increases in the DO concentration within Azevedo Pond due to biological activity indicate net photosynthesis, $\partial[\mathrm{DO}]_{\mathrm{p}} / \partial t=P S-R e . P S$ is calculated by adding the $[\mathrm{DO}]_{\mathrm{p}}$ removed by the $R e$ rate (calculated for the given water temperature) from $\partial[\mathrm{DO}]_{\mathrm{p}} / \partial t$ over each time interval (15 or $30 \mathrm{~min}$ ) evaluated. We selected 3450 observations from 3 series of data to estimate photosynthetic rate functions (September 9-October 9, 1996, May 10-21, 1997, and July 14-23, 1998). The data were filtered according to 5 conditions: (1) shortwave radiation must be greater than $10 \mathrm{~W} \mathrm{~m}^{-2}$ to eliminate variations at dawn or dusk $(\approx 0.1 \%$ of the maximum daily $Q_{\mathrm{sw}}$ value); (2) the depth change within the pond must be less than $5 \times 10^{-4} \mathrm{~m} \mathrm{~min}^{-1}$ to eliminate tidal influence; (3) $\partial[\mathrm{DO}]_{\mathrm{p}} / \partial t$ could not equal 0 ; (4) $P S$ could not be $\leq 0$; and (5) [DO $]_{p}$ must be greater than $2 \mu \mathrm{M}$ (to prevent $[\mathrm{DO}]_{\mathrm{p}}$ from providing a limit on $\left.\partial[\mathrm{DO}]_{\mathrm{p}} / \partial t\right)$. We also investigated developing a linear relationship between $P S$ as function of solar irradiance or water temperature. However, the variability of the data and previous studies on the dependence of $P S$ on both $Q_{\text {sw }}$ and $T_{\text {pond }}$ (Aruga 1965, Wetzel 1975) suggested that a temperature-dependent power function of $P S$ as a function of $Q_{\mathrm{sw}}$ was a better representation. Other researchers have described photosynthesis as being dependant upon the amount of light available, and water temperature sets an upper limit on the maximum photosynthetic rates obtained given enough light (Eppley 1972, Wetzel 1975, Geider 1987). Therefore, we grouped the 1407 data points that fit the selection criteria stated above by temperature $(<17,17-20$, $20-24,24-27$, and $>27^{\circ} \mathrm{C}$ ), and for each range $P s$ was plotted as a function of $Q_{\mathrm{sw}}$ (Fig. 6). We then fit each temperature range to a power function of the form $P_{S}$ $\left(\mu \mathrm{M} \min ^{-1}\right)=a\left[Q_{\mathrm{sw}}\left(\mathrm{J} \mathrm{m}^{-2} \mathrm{~s}^{-1}\right)\right]^{b}$. A Student's F-test statistically exceeded the $99 \%$ confidence interval for each of the independent $T_{\text {pond }}$ curve fits relative to a single curve ( $P S$ as a function of $Q_{\mathrm{sw}}$ ) for the entire data set, suggesting that breaking the data set into temperature intervals is justified.
Fig. 5. Respiratory oxygen removal $(R e)$ rate as a function of water temperature ( $\left.T_{\text {pond }}\right)$. The solid line is the best fit exponential of the data and the dotted line indicates the apparent maximum $R e$ rate for $T_{\text {pond }}>$ $24.5^{\circ} \mathrm{C}$. Data points represent means of 22 to 230 observations, with horizontal bars indicating temperature range represented and vertical bars indicating $1 \mathrm{SD}$ of the data

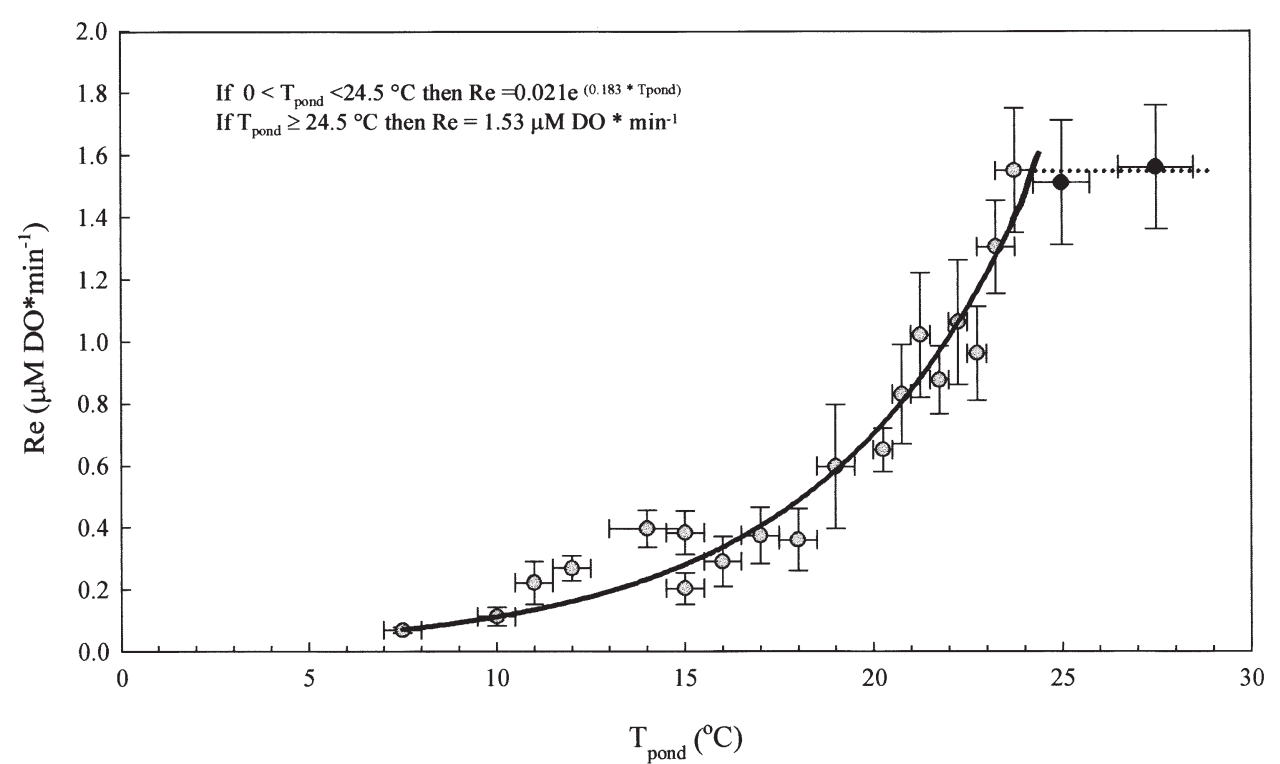



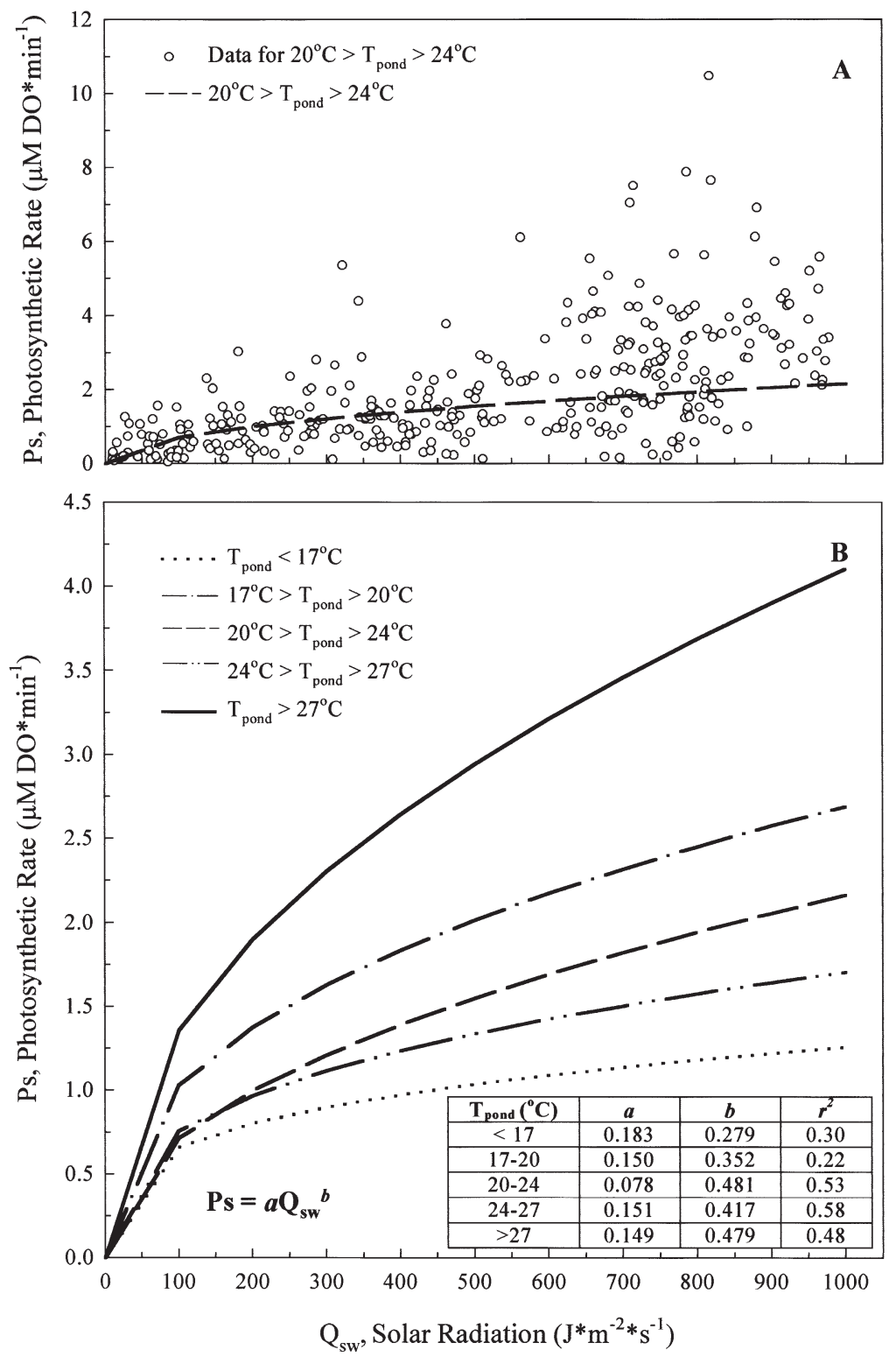

Fig. 6. Photosynthetic oxygen production $(P S)$ rate as a function of shortwave irradiance $\left(Q_{\mathrm{sw}}\right)$ and water temperature $\left(T_{\text {pond }}\right)$. (A) Data used to determine the empirical relationship between $Q_{\mathrm{sw}}$ and $P S$ for the $T_{\text {pond }}$ range of 20 to $24^{\circ} \mathrm{C}$. (B) Least-squares best-fit for 5 temperature intervals

D'Avanzo \& Kremer (1996) utilized high-resolution oxygen measurements to estimate community metabolism within 3 estuarine environments within the Waquiot Bay, Massachusetts. Their research of the diel $\mathrm{O}_{2}$ dynamics within the Childs River, an estuary receiving nitrogen enriched freshwater, suggested average $P$ s rates on the order of $0.5 \mu \mathrm{M} \mathrm{min}{ }^{-1}$ and average Re of $0.4 \mu \mathrm{M}$ $\mathrm{min}^{-1}$ during the summer month of July. Our empirical rates are somewhat greater than these (Figs 5 \& 6), but this may result from the relatively warm, nutrient, and carbon-rich conditions found at our field site.

\section{MODEL TUNING}

We tuned the model using time-series observations (July 4-22, 1998) of depth, water temperature, and dissolved oxygen collected in Azevedo Pond. Various parameters and values were manipulated to match modeled to observed values. We then evaluated the predictive capability of the model for an $11 \mathrm{~d}$ period in September 1996. We considered 3 main criteria when assessing the accuracy of the model for the September time series: (1) the mean value of the parameter over the entire simulation; (2) the daily maximum and minimum values of the parameter; and (3) the structure of curves, i.e., the general shape and the rates of change of the modeled parameters. In general, model predictions of water depth, temperature, and DO simulate the character of the measured time series, but there are misfits to the data in some instances. The mean misfit of the model and the degree of variance about the mean indicate how well the model matches observations. The first $72 \mathrm{~h}$ of each simulation are not reported, since these times are strongly influenced by initial conditions.

Five models are presented in the following sections (Table 5). We present 2 reference models (Cases R1 and R2) used to simulate the natural hydrologic, thermal, and oxygen response of Azevedo Pond to local climatic and tidal conditions. Case R1 includes entirely model-simulated pond depth, pond temperature, and pond DO concentrations. For Case R2, we substitute the observed $T_{\text {pond }}$ values into the model in order to improve the models ability to predict the DO budget within the pond. We then investigate the applications of the model to hypothetical scenarios (Cases $\mathrm{BA} 2, \mathrm{E}_{\mathrm{C}} 1$, and $\mathrm{WC} 1$ ) to evaluate the potential response of Azevedo Pond to various physical and chemical alterations. Parameter selection and other issues are discussed below.

\section{Water budget}

The pattern of depth observations suggests that pond inflow occurs rapidly, with an abrupt depth increase in response to rising tide. However, draining of the pond follows more of an exponential decay (Fig. 7A). These 
Table 5. Key components and results of model cases. $\mathrm{S}=$ used model predictions to simulate; $\mathrm{O}=$ used observed data to simulate. Parameters altered: parameters changed relative to standard model (R1). Suboxia: whether or not suboxic events occurred during simulation

\begin{tabular}{|c|c|c|c|c|c|c|}
\hline Case & Purpose & $V_{\text {pond }}$ & $T_{\text {pond }}$ & {$[\mathrm{DO}]_{\mathrm{p}}$} & Parameters altered & Suboxia \\
\hline $\mathrm{R} 1$ & Reference model & $\mathrm{S}$ & S & S & - & $\mathrm{Y}$ \\
\hline $\mathrm{R} 2$ & Reference model & $\mathrm{S}$ & $\mathrm{O}$ & S & - & $\mathrm{Y}$ \\
\hline BA2 & Reduced biological activity & $\mathrm{S}$ & $\mathrm{O}$ & S & $P S$ and $R e$ & $\mathrm{~N}$ \\
\hline $\mathrm{E}_{\mathrm{c}} 1$ & Lowered $E_{\mathrm{c}}$ & $\mathrm{S}$ & $\mathrm{S}$ & $\mathrm{S}$ & $E_{\mathrm{c}}$ & $\mathrm{N}$ \\
\hline WC1 & Warmer climate & $\mathrm{S}$ & $\mathrm{S}$ & $\mathrm{S}$ & $v_{\mathrm{a}}, Q_{\mathrm{sw}}, T_{\mathrm{air}}$ & $\mathrm{Y}$ \\
\hline
\end{tabular}

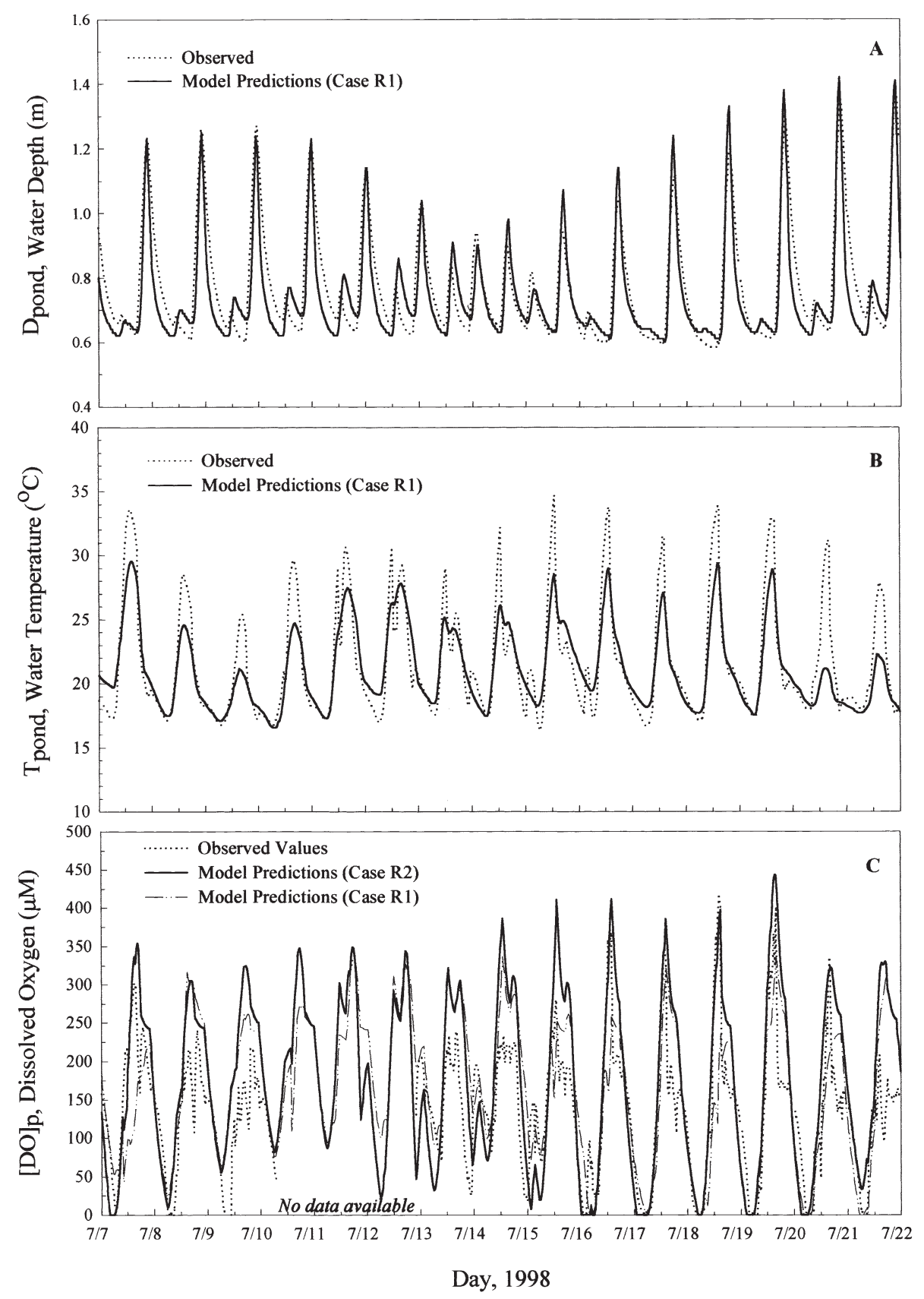

Fig. 7. In situ data and model calculations for Azevedo Pond (July 7-22, 1998). (A) Water depth ( $D_{\text {pond }}$ ); (B) water temperature $\left(T_{\text {pond }}\right) ;(\mathrm{C}) \mathrm{DO}$ concentration $\left([\mathrm{DO}]_{\mathrm{p}}\right)$ 
behaviors may result from the geometry of the bottom of the tidal channel, including the presence of vegetation in the flow path. In order to decrease the flow rate at shallow water depths, the Manning roughness coefficient $(n)$ was increased when the water in the inlet channel was low, simulating the greater influence of dense vegetation at low flow rates (Eq. 1.9).

Model predictions of Azevedo Pond depth as a function of time during July 1998 fit observations quite well, with a misfit below the observed mean of $0.015 \pm$ $0.066 \mathrm{~m}$ (Fig. 7A). We then input local weather and tidal data from September 1996 to test the predictive capability of the water volume model. Interestingly, pond depth predictions from the model suggested that the minimum depth of Azevedo Pond was approximately $0.35 \mathrm{~m}$ shallower than recorded by the in situ probe. This discrepancy suggests that from September 1996 to July 1998, the inlet channel eroded at a rate of $16 \mathrm{~cm} \mathrm{yr}^{-1}$, consistent with observations at the site. Lowering of the culvert elevation connected to Azevedo Pond over this time period has increased tidal flushing and helps to explain the decrease in the duration and occurrence of suboxic events over the last $4 \mathrm{yr}$ (ESNERR unpubl. data). Fig. 8A shows the water volume variations predicted within Azevedo Pond from September 24 to October 5, 1996, following an increase in the culvert elevation of $0.24 \mathrm{~m}$ from the model developed using the 1998 time-series data.

\section{Heat budget}

Daily water temperature patterns within Azevedo Pond display steep increases during the morning hours, reach midday maximum values, and then decline gradually throughout the nighttime hours until shortly after sunrise (Fig. 7B). The model produces a good fit to baseline water temperatures for July 1998, but fails to predict the full range of daily temperatures recorded within the pond (Fig. 7B). During the September/October 1996 simulation, the model $T_{\text {pond }}$ structure predicts the daily maximum temperatures measured in the pond, but fails to remove enough heat from the pond at night (Fig. 8B).

The misfits of model heat predictions probably results from 2 main problems. Because the in situ probe is held at a fixed depth, the location of the observed measurements varied with tidal height and may not be representative of the average pond temperature. In contrast, the model predicts a volumetric average water temperature within the pond. Another potential explanation for the $T_{\text {pond }}$ misfit is that the weather station is located $18 \mathrm{~km}$ southwest of Azevedo Pond, at Fort Ord, California. Both the weather station and Azevedo Pond are located 5 to $10 \mathrm{~km}$ from the coast, but Monterey Bay weather patterns are heterogeneous, and coastal fog pockets may persist in isolated locations. Fog over the pond would reduce both shortwave radiation and ambient air temperatures during the daylight hours, 2 key parameters controlling daily maximum $T_{\text {pond }}$ values.

\section{Dissolved oxygen budget}

DO model tuning

The time series data from July 1998 was used to calibrate the DO budget, and the model was tested using the September/October1996 data. The structure of the flushing signature shoulder on the DO curve (i.e., $[D O]_{p}$ near atmospheric saturation) was not reproduced during initial simulations. In order to match observed DO variations, we had the model shut down both $P_{S}$ and $R e$ when the flux of water into Azevedo Pond was greater than $10 \mathrm{~m}^{3} \mathrm{~min}^{-1}$, reasoning that biological activity will be greatly reduced by high turbidity and rapid circulation.

Two reference simulations (Cases R1 and R2) for the DO budget are presented. Case R1 uses modelpredicted $T_{\text {pond }}$ values, while Case R2 uses observed $T_{\text {pond }}$ values. The failure of model Case R1 to predict the full range of observed pond temperatures (Figs 7B $\& 8 \mathrm{~B}$ ) does not allow an accurate assessment of the empirical relationships we derived to predict biological metabolism, due to the strong dependence of the DO budget on water temperatures (see Figs 5 \& 6). Model Case R2 allows us to evaluate the consistency of the empirical biological metabolism rates (Figs 7C \& 8C).

For July 1998 (Fig. 7C), both simulations slightly overpredict $[\mathrm{DO}]_{\mathrm{p}}$ in the pond, but the use of observed $T_{\text {pond }}$ values (Case R2) improved the model's match to the observed DO variations during this time period. In running the model with the September/October 1996 time series (Fig. 8C), both Case R1 and Case R2 slightly overpredict the first $5 \mathrm{~d}$ of the observed $[\mathrm{DO}]_{\mathrm{p}}$ timeseries and fail to capture the daily maximum $[\mathrm{DO}]_{\mathrm{p}}$ values during the suboxic events of October 3-5, 1996. The model was unable to reproduce the large $[\mathrm{DO}]_{\mathrm{p}}$ peaks recorded during the late afternoon on sequential days of nighttime suboxia (Figs 7C \& 8C). These peaks may result from brief supersaturation of localized surface waters, a condition not captured by a model of the average $[D O]_{p}$ within the entire pond. Although there are obvious model misfits during times of extremely high $[D O]_{p}$ values, the model does recreate the general daily structure of the DO budget within this dynamic system. For the 15 suboxic events recorded during the time periods presented, the model correctly predicted 12 (Figs 7C \& 8C). 

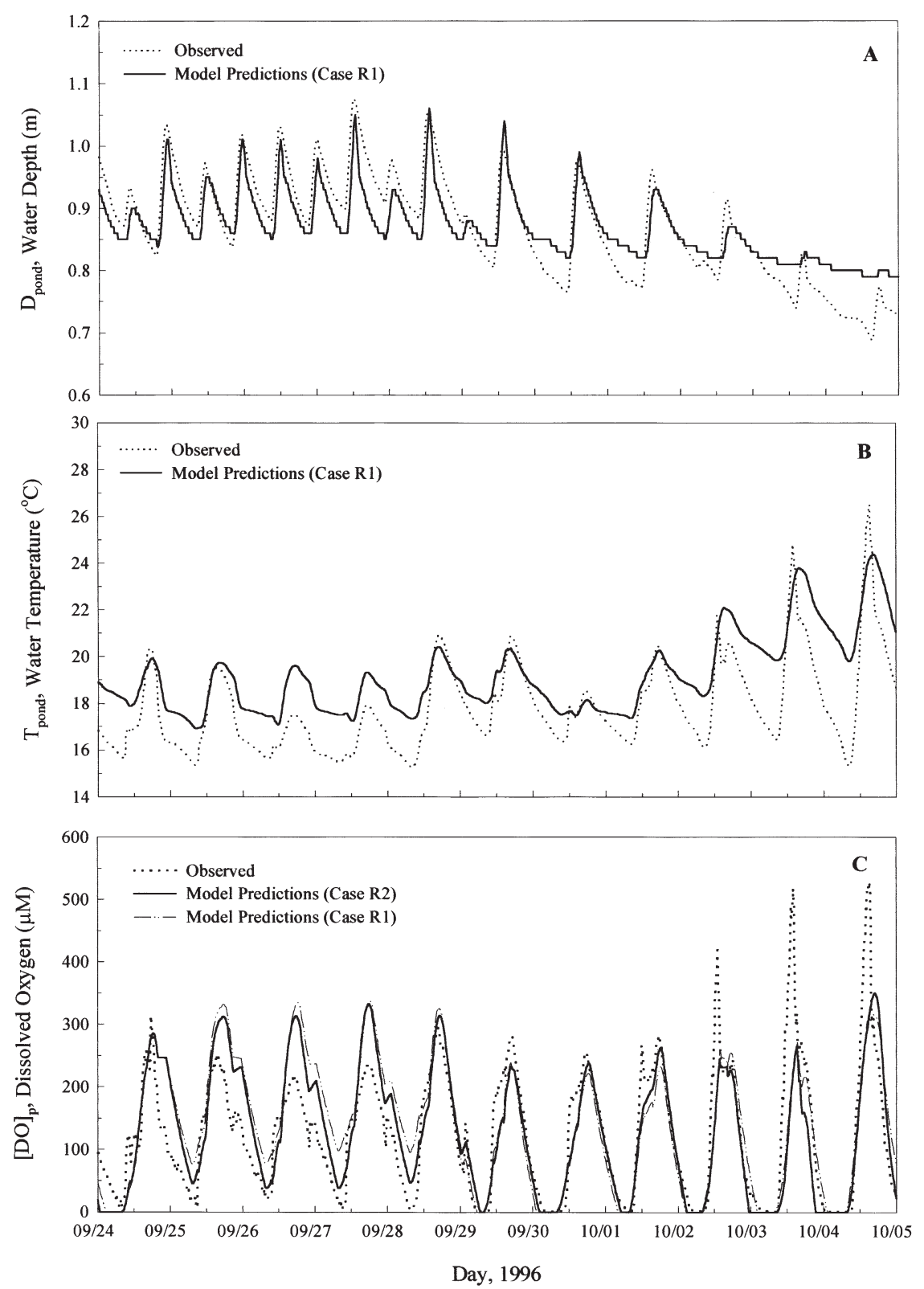

Fig. 8. In situ data and model calculations for Azevedo Pond (September 24-October 5, 1996). (A) Water depth ( $D_{\text {pond }}$; (B) water temperature $\left(T_{\text {pond }}\right)$; $(\mathrm{C})$ DO concentration $\left([D O]_{p}\right)$

\section{DO budget dynamics}

The DO budget within Azevedo Pond is controlled by the interaction of physical and biological processes. The daily DO peaks are the result of maximum net photosynthetic oxygen production (i.e., the rate of oxygen production in excess of respiratory utilization). Respiration occurs continually throughout the day and is responsible for the daily minimum DO values at night when $P S=0$ (Fig. 9). Superimposed on the daily DO highs and lows are tidal flushing events, which are represented by the introduction of water with $\mathrm{O}_{2}$ concentrations near atmospheric saturation. A flushing signature on the DO curve will either decrease the DO concentration of the pond during times of elevated net photosynthetic oxygen production or increase the DO concentration when respiration dominates and $[\mathrm{DO}]_{\mathrm{p}}$ is below saturation. Gas exchange with the atmosphere would tend to dampen the daily DO oscillations as a result of degassing during supersaturated peaks and 'in gassing' during undersaturated lows (i.e., suboxic periods). Both dissolved oxy- 


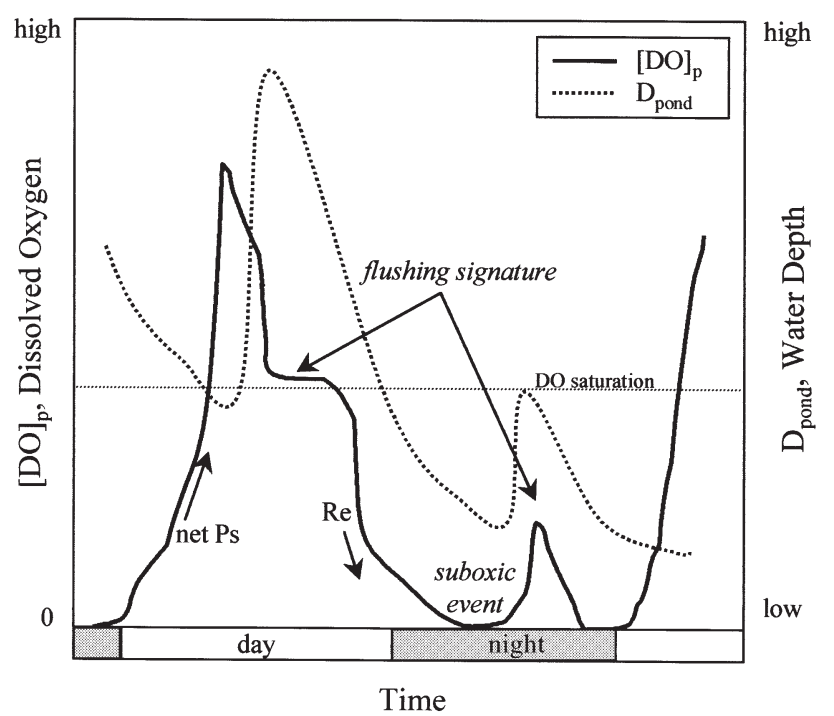

Fig. 9. Schematic illustrating features of a typical dissolved oxygen curve structure recorded in Azevedo Pond during warm summer months

gen budgets estimated by Kemp \& Boyton (1980) and our model suggest that DO diffusion from gas exchange is relatively minor and accounts for only about $5 \%$ of the daily DO variations.

Suboxic events in Azevedo Pond only occur during neap tidal cycles in the warm summer months, when 2 physical conditions are satisfied. First, water temperatures must be high enough to elevate respiration rates. The dependence of suboxic events on warmer water is illustrated by the lack of measured suboxia in Azevedo Pond during the colder months of November through April. Second, suboxic conditions can be prevented and/or alleviated by the introduction of relatively oxygen-rich waters (Fig. 9). The daily timing of the high tides advances throughout the month. When there is no nighttime flushing event during a warm period, biological respiration dominates the DO budget and results in water column suboxia until shortly after sunrise.

\section{APPLICATIONS OF THE MODEL}

\section{What would it take to alleviate suboxia in Azevedo Pond?}

Nutrient enrichments associated with agricultural runoff and extended water residence times from tidal restrictions tend to amplify natural diel DO variations and may hinder the functional and ecological stability of this system. We now apply the box model as a tool to evaluate the implications of physical and chemical alterations on diel DO dynamics within Azevedo Pond. There are 3 ways in which the hyperventilation events in Azevedo Pond could be eliminated: (1) increase physical mixing, (2) decrease nutrient inputs to limit biological activity, and (3) decrease water temperatures.

Ideally, the physical restoration of this stressed wetland environment would result in the improvement of all 3 of the conditions. We can easily model the effects of increased water circulation by lowering the culvert elevation $\left(E_{c}\right)$. Rigorously modeling the daily effects of nutrient limitations on community metabolism would require expanding our observed data sets and model structure. However, we can simulate nutrient limitations by decreasing the $P s$ and Re rates. Decreased water temperatures would be a secondary result of increasing tidal mixing within Azevedo Pond and would also lower biological metabolic rates. Observations suggest that suboxia does not occur in the cold winter months, when $T_{\text {pond }}$ values are, on average, nearly $10^{\circ} \mathrm{C}$ colder. Below we present the hydrologic and geochemical response of Azevedo Pond to increased mixing (Case $\mathrm{E}_{\mathrm{c}} 1$ ) and decreased biological activity (Case BA2).

\section{Model Case $\mathrm{E}_{\mathrm{C}} 1$}

Physically decreasing the residence time of the water in Azevedo Pond would reduce or eliminate the occurrence of suboxic events. If the pond was better connected to the daily tidal cycle, water circulation would increase and the pond would not remain stagnant for periods of up to $12 \mathrm{~h}$. A simple way to increase mixing is to reduce the elevation gradient of the inlet channel and increase the occurrence and duration of tidal flushing.

We used the October 1996 data to drive Model Case $E_{c} 1$ over a range of culvert elevations and determined the critical culvert elevation necessary to eliminate suboxia was $0.96 \mathrm{~m}$, a lowering of just $12 \mathrm{~cm}$. This physical change allowed every high tide to breach the culvert and introduce oxygenated water from the main channel to the pond. The minimum depth of the pond was decreased to $0.5 \mathrm{~m}$, significantly increasing the duration and magnitude of tidal mixing. Increasing mixing decreased the average $T_{\text {pond }}$ by $0.8^{\circ} \mathrm{C}$ relative to observations (Fig. 10A, Case $\mathrm{E}_{\mathrm{C}} 1$ ). Most importantly, suboxic periods were eliminated entirely and increased tidal mixing maintained $[\mathrm{DO}]_{\mathrm{p}}$ values closer to saturation levels (Fig. 10B, Case $\mathrm{E}_{\mathrm{C}} 1$ ).

As discussed earlier, the culvert elevation at Azevedo Pond was approximately $0.24 \mathrm{~m}$ lower in July 1998 than it was in October 1996. As a result of this erosion, the pond deepened and the amount of flush- 

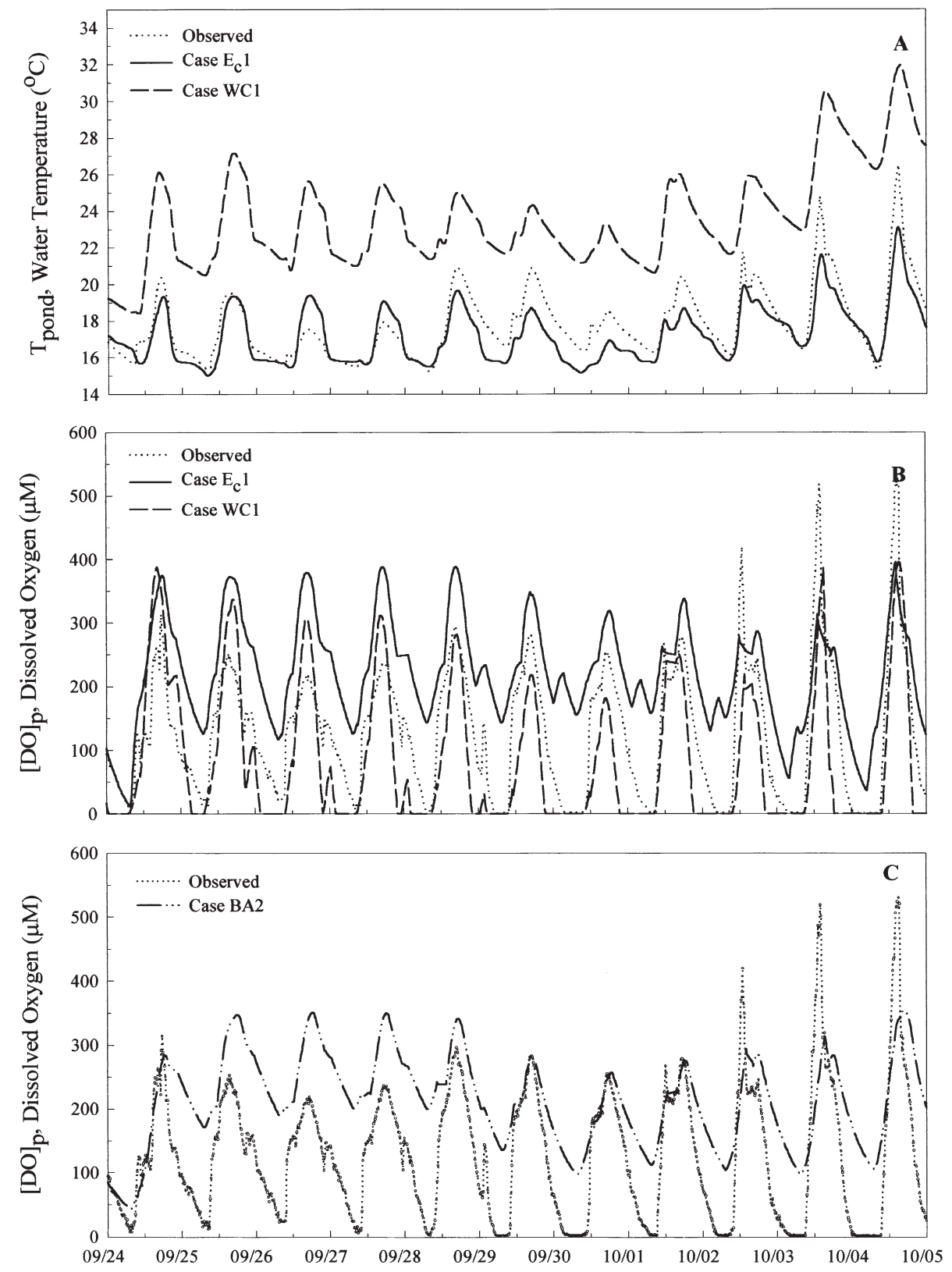

Fig. 10. Reference model data versus modeled predictions given various physical alterations of Azevedo Pond for September 24 -October 5, 1996. (A) Water temperature ( $\left.T_{\text {pond }}\right)$ from reference Case R1 compared to Cases $E_{C} 1$ and WC1. (B) DO concentration $\left([D O]_{p}\right)$ from Case R1 compared to Cases $E_{c} 1$ and WC1. (C) Decreasing biological activity (Case BA2) compared to Case R2 (observed $T_{\text {pond }}$ )

ing increased, corresponding to a decrease in the number and duration of suboxic events in 1998. The in situ hydrographic probe in the main channel of Elkhorn Slough, located $3.5 \mathrm{~km}$ from the mouth of the Slough (Fig. 1), is not tidally restricted and experiences the full magnitude of daily tidal variations. This location possesses similar eutrophic $\mathrm{N}$ and $\mathrm{P}$ concentrations to Azevedo Pond, yet over the 5 yr of data collection, no suboxic events have been recorded. A study of over 50 estuarine systems worldwide has shown a direct correlation between the degree of circulation and the ability of the estuary to handle elevated levels of nitrate, and not display production rates typical of eutrophic systems (Monbet 1992). The different tidal environments within Elkhorn Slough provide further support for the critical dependence of biological metabolism (i.e., diel DO stability) on tidal flushing in shallow nutrient-rich environments. 
Model case BA2

Decreasing nutrient inputs are another potential restoration mechanism to eliminate extreme diel DO variations. Pristine salt-marsh environments are often nitrogen-limited and show increased algal growth with nitrogen additions (Schlesinger 1997). One mechanism for decreasing $P S$ and $R e$ rates, and therefore total biomass in Azevedo Pond, would be to decrease the nitrogen $(\mathrm{N})$ inputs. In an N-limited system, daily Ps rates would be dependent upon $N$ concentrations, in addition to $T_{\text {pond }}$ and $Q_{\mathrm{sw}}$. Daily $R e$ would vary as a function of both $T_{\text {pond }}$ and the supply of organic carbon produced by the subsequent periods of primary production. In order to properly model the effects of N limitation on the biological metabolism, we would need to include both $\mathrm{N}$ and $\mathrm{C}$ budgets. Unfortunately, we lack $\mathrm{N}$ and $\mathrm{C}$ flux or storage data to guide construction of independent budgets for these parameters in Azevedo Pond. However, we can decrease the Ps and Re rates to indirectly evaluate the implications of nutrient limitation on the kinetics of biological metabolism (Case BA2). After experimenting with a range of decreased $P s$ and $R e$ rates, we found that lowering metabolic activity by $35 \%$ completely eliminated suboxic conditions in Azevedo Pond and allowed the maintenance of more stable $[\mathrm{DO}]_{\mathrm{p}}$ values, even during times of elevated water temperatures and tidal restrictions (Fig. 10C).

Fig. 11 is a schematic of different forms of the dependence of Ps on shortwave radiation in both eutrophic and N-limited systems. In a eutrophic system such as Azevedo Pond, Ps is dependent upon both $Q_{\mathrm{sw}}$ and $T_{\text {pond, }}$ but reaches a maximum value above a critical $Q_{\mathrm{sw}}$ value (Figs $6 \& 11$, curve A). We suspect that if

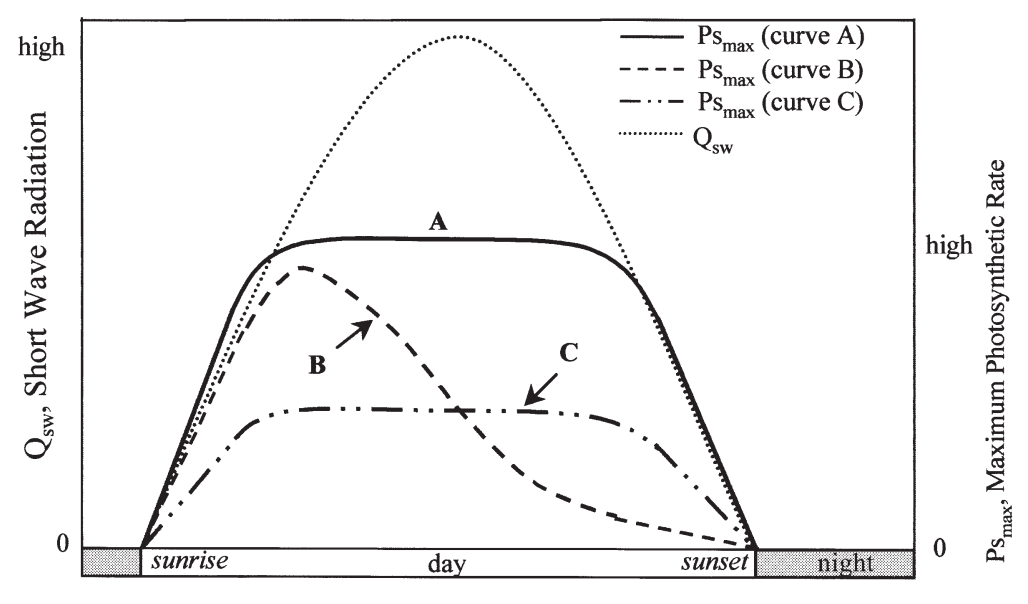

Time

Fig. 11. A schematic illustrating the dependence of maximum $P_{S}$ on $Q_{\mathrm{sw}}$ (for any given $T_{\text {pond }}$ )
Azevedo Pond were N-limited, Ps would reach a daily maximum immediately following the $Q_{\mathrm{sw}}$ peak, but then decrease as the limiting nutrient, N, is gradually consumed by primary productivity (Fig. 11, curve B). Respiratory regeneration of $\mathrm{N}$ during the previous night provides $\mathrm{N}$ concentrations high enough to promote elevated $P S$, but as $\mathrm{N}$ uptake continues and is removed from the system, $\mathrm{N}$ availability will limit maximum $P$ s rates. We have modeled this behavior as an overall reduction in both $P S$ and Re rates (Fig. 11, curve C); thus for the same $T_{\text {pond, }}$ the decreased uptake kinetics due to $\mathrm{N}$ limitation would decrease the daily maximum $P_{S}$. The goal of future modeling efforts should include diel nutrient variations as they respond to biological metabolism, with a response more like curve B (Fig. 11).

\section{How would Azevedo Pond respond to a warmer climate?}

From our investigations of Azevedo Pond, suboxic conditions are more likely to occur during days of intense solar radiation input and elevated ambient air temperatures (Beck \& Bruland 2000). We are interested in the thermal and geochemical response of Azevedo Pond if it were subjected to a consistently warmer climate. Model WC1 was run using all of the September/October 1996 tidal and weather data except for air temperature, shortwave radiation, and wind speed data. For these parameters, we substituted data from a site in Alviso, California $(70 \mathrm{~km} \mathrm{NE}$ of Azevedo Pond). The Alviso weather station is located at sea level near South San Francisco Bay and is less influenced by coastal weather patterns than Azevedo Pond. On average, $T_{\text {air }}$ was $4.2^{\circ} \mathrm{C}$ warmer and shortwave irradiance was $120 \mathrm{~W} \mathrm{~m}^{-2}$ higher during the simulated time period.

Warmer climatic conditions result in daily $T_{\text {pond }}$ values (Fig. 10A, Case WC1), of 21 to $32^{\circ} \mathrm{C}$, an average of $5.9^{\circ} \mathrm{C}$ warmer than observed values. The model predicts suboxic conditions every night over the $10 \mathrm{~d}$ simulation period (Fig. 10C, Case WC1). In contrast, suboxic events were observed on only 6 nights. Due to significant increases in $T_{\text {pond }}$ values (Fig. 10A), modeled $R e$ rates have a stronger influence on dissolved oxygen dynamics during daylight hours, resulting in daily maximum $[\mathrm{DO}]_{\mathrm{p}}$ similar to the values observed in Azevedo Pond.

The scenarios described above illustrate the importance of water circulation and climate on short-term oxygen stability 
within a shallow aquatic system. Azevedo Pond periodically experiences suboxic conditions when warm sunny days are coupled with low early morning high tides. The duration of nighttime suboxia is dependent upon water temperature and the extent of biomass loading from previous days. Suboxia will not occur in Azevedo Pond if early morning stagnant water periods are preceded by foggy coastal weather, when respiring bacteria are limited by low biomass (D'Avanzo \& Kremer 1994, Beck \& Bruland 2000). Increasing circulation (Case $E_{c} 1$ ) and decreasing biological activity (Case BA2) both eliminated suboxia in Azevedo Pond (Fig. 10B). Model WC1 illustrates that a warmer climate could elevate biological activity and increase both the occurrence and duration of suboxic events (Fig. 10C). In a warmer climatic regime, additional increases in water circulation would be necessary to counteract elevated $T_{\text {pond }}$ and $Q_{\mathrm{sw}}$ values and prevent suboxia. Although the qualitative results of these simulations are not surprising, the model provides a quantitative assessment of the critical elevation of the culvert necessary to eliminate stagnant periods and the response of the system to interactions of physical changes such as decreased nutrient inputs and increased water circulation.

\section{CONCLUSION}

The methodology presented herein shows how physical and chemical variations within a wetland environment can be modeled using limited ancillary water quality, tidal, and climatic data. We recognize that this research only touches on the potential modeling opportunities for these systems. The heat budget would be greatly improved with a weather station at the site, and the oxygen budget should be complemented with carbon and nutrient budgets. Future efforts to create predictive tools for wetland chemical dynamics should include seasonal carbon, nitrogen, and phosphorus data in order to create these essential budgets. With the addition of detailed nutrient data, these models could aid difficult management decisions such as quantifying the critical annual nutrient flux allowable to maintain DO variations indicative of a healthy ecosystem.

Given the time and financial constraints of many environmental restoration projects, the methodology presented here would provide a useful and relatively simple means to evaluate system dynamics and potential responses to various restoration alternatives. In addition, pre-restoration data collection, water quality studies, and predictive models will provide baseline time-series data of the physical and chemical dynamics of the system, and greatly assist in assessing the bene- fit and effectiveness of subsequent restoration efforts. For example, the ability to evaluate the amount of tidal flushing or the critical water depth necessary to maintain a stable geochemical environment could aid wetland design and improve the longevity and health of the modified ecosystem. A model could also be used as a tool to predict the biogeochemical response to climatic variations or alterations to the physical characteristics of a shallow wetland system. All too often it appears that 'restoration' efforts in wetland systems are conducted with minimal understanding of the fundamental physical and biological processes controlling the geochemical health of the system in question. The method we describe allows an initial assessment of the processes influencing the DO budget and allows investigation of the potential response of the system to various alterations.

Acknowledgements. We appreciate the cooperation and data contributions from both the Elkhorn Slough National Research Reserve (ESNERR) and the University of California at Santa Cruz (UCSC) Real-time Environmental Information Network and Analysis System (REINAS) project. This work was supported by the Harbor Processes Program of ONR grant \#N00014-99-1-0035 and UC Toxics Substances Teaching Program grant \#98R-12. This manuscript was greatly improved by numerous thoughtful suggestions from an anonymous MEPS reviewer.

\section{LITERATURE CITED}

Anisfeld SC, Benoit G (1997) Impacts of flow restrictions on salt marshes: an instance of acidification. Environ Sci Tech 31:1650-1657

Aruga Y (1965) Ecological studies of photosynthesis and matter production of phytoplankton. II. Photosynthesis of algae in relation to light intensity and temperature. Bot Mag Tokyo 78:360-365

Beck NG, Bruland KW (2000) Diel biogeochemical cycling in a hyperventilating shallow estuarine environment. Estuaries 23:177-187

Broeker WS, Peng TH (1982) Tracers in the sea. LamontDoherty Geological Observatory, New York

Cooper SR, Bush GS (1991) Long-term history of Chesapeake Bay Anoxia. Science 254:992-996

D'Avanzo C, Kremer JN (1994) Diel oxygen dynamics and anoxic events in an eutrophic estuary of Waquoit Bay, Massachusetts. Estuaries 17:131-139

D'Avanzo CD, Kremer JN, Wainright SC (1996) Ecosystem production and respiration in response to eutrophication in shallow temperate estuaries. Mar Ecol Prog Ser 141: 263-274

Dingman SL (1994) Physical hydrology. Prentice-Hall, Englewood Cliffs, NJ

Dunne T, Leopold L (1978) Water in environmental planning. WH Freeman and Co, San Francisco, CA

Eppley RW (1972) Temperature and phytoplankton growth in the sea. Fish Bull 70:1063-1085

Fetter CW (1994) Applied hydrogeology. MacMillan, New York

Geider RJ (1987) Light and temperature dependence of the 
carbon to chlorophyll a ratio in microalgae and cyanobacteria: implications for physiology and growth of phytoplankton. New Phytol 106:1-34

Kemp WM, Boyton WR (1980) Influence of biological and physical processes on dissolved oxygen dynamics in an estuarine system: implications for measurement of community metabolism. Estuar Coast Mar Sci 11:407-431

Monbet Y (1992) Control of phytoplankton biomass in estuaries: a comparative analysis of microtidal and macrotidal estuaries. Estuaries 15:563-571

Montague CL, Zale AV, Percival MV (1987) Ecological effects of coastal marsh impoundments: a review. Environ Manage 11:743-756

Odum EP (1971) Fundamentals of ecology. WB Saunders Co, Philadelphia

Officer CB, Biggs RB, Taft JL, Cronin LE, Tyler MA, Boynton WR (1984) Chesapeake Bay anoxia: origin, development, and significance. Science 223:22-27

Editorial responsibility: Otto Kinne (Editor),

Oldendorf/Luhe, Germany
Philip Williams \& Ass. Ltd. (1993) Enhancement plan for the Azevedo marshes: hydrologic elements. Technical Report, Philip Williams \& Ass., San Francisco, CA

Platt T, Denman KL, Jassby AD (1975) Modeling the productivity of phytoplankton. In: Goldberg ED (ed) In the sea: ideas and observations on progress in the study of the seas. John Wiley, New York, p 807-856

Roelke DL, Eldridge PM, Cifuentes LA (1999) A model of phytoplankton competition for limiting and nonlimiting nutrients: Implications for development of estuarine and nearshore management schemes. Estuaries 22:92-104

Schlesinger WH (1997) Biogeochemistry; an analysis of global change. Academic Press, San Diego, CA

Stumm W, Morgan JJ (1996) Aquatic chemistry; chemical equilibria and rates in natural waters. John Wiley and Sons, New York

Wetzel RG (1975) Limnology. WB Saunders Company, Philadelphia, PA

Submitted: August 10, 2000; Accepted: April 19, 2001

Proofs received from author(s): July 11, 2001 